\title{
Bedside Nursing Handover: A Case Study
}

\section{Running Title: Bedside Nursing Handover}

\section{Authors:}

Wendy Chaboyer, $\mathrm{PhD}, \mathrm{RN}$

Director, Research Centre for Clinical and Community Practice Innovation, Griffith University, Gold Coast Campus, Queensland, Australia, 4222

\section{Anne McMurray, PhD, RN, FRCNA}

Professor and Research Chair in Nursing, Murdoch University, Mandurah, Western Australia Adjunct Professor, Research Centre for Clinical and Community Practice Innovation, Griffith University, Gold Coast, Queensland, Australia

Marianne Wallis, $\mathrm{PhD}, \mathrm{RN}$

Professor, Research Centre for Clinical and Community Practice Innovation, Griffith University, Gold Coast, Queensland, Australia

Corresponding author: Professor Wendy Chaboyer

Research Centre for Clinical and Community Practice Innovation, Griffith University Gold Coast Campus,

Griffith University, Queensland 4222, Australia

Telephone:617-55528518, Fax: 617-55529144

Email: W.Chaboyer@griffith.edu.au,

Keywords: clinical handover, nursing handover, bedside handover, transforming care at the bedside 


\begin{abstract}
A case study of six wards in two hospitals was undertaken to describe the structures, processes and perceptions of outcomes of bedside handover in nursing. A total of 532 bedside handovers were observed and 34 interviews with nurses conducted. Important structural elements related to the staff, patients, the handover sheet and the bedside chart. A number of processes prior to, during, and after the handover were implemented. They included processes for managing patients and their visitors, sensitive information, and the flow of communication for variable shift starting times. Other key processes identified were the implementation of a safety scan and medication check. The situation, background, assessment, recommendations (SBAR) approach was used only in specific circumstances. Perceived outcomes were categorised as improving accuracy and service delivery, and promoting patient centred care. While the move to bedside handover is not the norm, it demonstrates a patient centred approach.
\end{abstract}

Keywords: nursing handover, clinical handover, bedside handover, clinical nursing research 


\section{Bedside Nursing Handover; A Case Study Introduction}

Effective communication amongst health professionals is key to ensuring quality care in clinical practice ${ }^{1,2}$. One form of communication, clinical handover, has received increasing international attention. ${ }^{1-3}$ Clinical handover has been defined as the transfer of responsibility and/or accountability for patient care from one provider or team of providers to another. ${ }^{4}$ Nursing handover at the bedside has been identified as an important strategy to improve patient-centered care,${ }^{5}$ one aspect in the Institute for Healthcare Improvement’s Transforming Care at the Bedside (TCAB) program. ${ }^{5,6}$ We report here on a case study of six wards in two hospitals investigating the structural elements, processes used to transfer knowledge, and perceived outcomes of bedside nursing handovers.

\section{Bedside Handover in Nursing}

The body of research on nursing handover has focused on comparing various types of handovers such as face to face verbal (office or bedside), and audio-taped, ${ }^{7-10}$ and on the functions and problems in maintaining accurate communication in handovers. ${ }^{7,11,12}$ Some believe verbal handovers to be unreasonably lengthy, often including non-essential and irrelevant information instead of reliable, accurate information based on patient documentation. ${ }^{9,13}$ Like some verbal handovers, audiotaped handovers can also be confined to ritualistic, retrospective, treatment oriented information rather than providing focus and direction for forward planning, ${ }^{14}$ although these are less time consuming because of fewer interruptions. ${ }^{15}$ Researchers have examined nurses' views of the difference between verbal, recorded and bedside handovers or combinations of these. ${ }^{16}$ Handover can be an opportunity for mentoring junior staff members, to socialize newcomers into the culture of nursing, helping them learn professional goals and values and provide a forum for developing group 
cohesion. ${ }^{10,12}$ One of the purported advantages of bedside handovers is the opportunity for student teaching. In this style of handover students begin to see nursing as something done with rather than for patients. ${ }^{16}$

Some researchers believe bedside handovers are more accurate and time-effective ${ }^{16-18}$ but a number of contentious issues have also been highlighted. Criticisms of bedside handover include a perception that bedside handovers are too time ${ }^{9}$ and resource intensive, ${ }^{19}$ that there are difficulties associated with staff members having little awareness, knowledge and/or skills in 'partnering' with patients, and that patient involvement will undermine the clinician-patient relationship. ${ }^{19}$ Others argue that the jargon of handover might promote anxiety or confusion among patients, ${ }^{16,20}$ or that careless conversations at the bedside that may disturb patient confidence. ${ }^{16}$ Over 15 years ago, Parker et al's ${ }^{21}$ Australian study concluded that bedside handover was less efficient as it was often simply a recitation of fact rather than interpretation of the patient's condition, but Watkins ${ }^{22}$ countered this with the argument that it reduces the amount of time spent in the office chatting. Cahill ${ }^{16}$ adds support for bedside handover in terms of student learning, where role models are seen to be providing patient centred, collaborative care. Beneficial effects such as patients gaining a better understanding of their care plans, better discharge planning and more supportive team leaders were also identified in a recent description of how bedside nursing handover was implemented in one hospital. $^{3}$

Although bedside handover is favoured by a patient-centred approach and provides patients with an opportunity to discuss their own care $^{9}$, there is limited information about its implementation and evaluation, thus, this research aimed to better understand the structures processes and perceived outcomes of bedside nursing handover as a beginning step to facilitate its implementation. 


\section{Methods}

We used a descriptive case study ${ }^{23}$ of bedside nursing handover in three wards in each of two relatively large Australian hospitals (six wards total). Case study was chosen as appropriate to the intention of the study. It is a methodological approach that often uses mixed methods to conduct an instrumental investigation bounded by place and time. ${ }^{23,24}$ Case study research asks questions of 'what', 'why' and 'how' in a non-controlled or artificial environment to analyse existing, real-life situations with all their complexity. ${ }^{25}$ Through iterative review, the analysis yields a detailed, descriptive, comprehensive chain of evidence explaining the findings in terms of the conceptual framework chosen to guide the analysis. ${ }^{23}$ Donabedian's ${ }^{26}$ framework for the evaluation of quality of performance in delivering health care services was used to conceptualise the study. It is comprised of three elements; structure, process and outcome. Assessing quality is undertaken by appraising structures and processes and linking these to outcomes, with the assumption that structures influence processes, which, in turn, influence outcomes. Structures include the physical and organisational properties, processes are what is actually done, and the outcome is what is accomplished. Evaluating an aspect of quality or a system is aimed at causal relationships between the three elements; that is, the structures and processes are responsible for outcomes. In this study, outcomes as perceived by participants were identified. The study took place on medical, surgical and rehabilitation wards that had predominantly six beds per room, with a few single and double rooms. In one hospital, team nursing was used and bedside handover had been used for over a year. In the other, a variety of nursing models were used and bedside handover had just been instituted, superseding verbal handover in a staff room. Bedside nursing staff, team leaders (i.e. those responsible for a subgroup of patients and nursing staff), shift coordinators (who took overall responsibility for ward functioning, often concurrently with team leadership 
duties), nursing managers and educators, were the focus of this study. All participants consented to participate in the study.

\section{Data Collection}

Two forms of data collection were used, semi-structured observation and interviews. These were confined to nursing staff because of the non-attendance at handover of medical and allied health staff; although optimally, all disciplines would have been included for a multi-disciplinary approach. Including patient perspectives was also beyond the scope of the study but is the subject of another current investigation. Because of the reduced staff during other handovers, only the afternoon shift-to-shift handover was included, but interview data included participants’ views about the other handovers. Clinical research assistants conducted the bedside observations guided by a data collection form recording the numbers and classifications of oncoming and outgoing staff, content of the information handed over

including the use of situation, background, assessment and recommendations (SBAR), ${ }^{27,28}$ the time spent at the bedside and the patients' input. When patients asked questions, or made statements about their conditions they were judged to be actively participating in the handover. If they simply nodded or made short, superficial comments such as 'hello' they were considered to be passive participants. When there was no form of patient input, patients were deemed to have not been involved in the handover.

Audio-taped in-depth interviews were conducted with a purposive sample of nursing staff involved in the handovers. Questions sought to explore both structure and process issues related to communicating patient information during the handover in addition to their perceived outcomes. Examples of questions are listed below.

- How do you prepare for handover, both when you are handing over and receiving handover? 
- How do you ensure the accuracy of the handover information?

- To what extent do you include the patient's input or opinions in handover?

- How do you deal with the presence of family members?

- What strategies do you have for maintaining patient privacy in multiple bed rooms?

- Can you describe night, morning and afternoon shift variations?

\section{Data Analysis}

Observational data were analysed through iterative review by all members of the research team. . Interviews were analysed using content analysis where data were grouped around central, recurrent ideas. ${ }^{23,29}$ This analysis was also iterative, with all members of the research team examining theinterview data in a recursive manner, searching for similarities in the views ofrespondents and across the six cases using constant comparison. Similar ideas were then organised into categories of structures, processes and perceived outcomes

\section{Results}

A total of 532 bedside handovers were observed on three medical, one surgical, one combined medical surgical and one rehabilitation ward, with slightly more than half on the medical wards (Table 1). At one hospital SBAR ${ }^{27,28}$ was used in varying degrees, from $45 \%$ to $65 \%$ of the handovers, in three situations when: 1) patients were new or their conditions had changed; 2) patients were unfamiliar to staff such as when staff had been off for a few days; or 3) casual/agency staff were part of the team. Patients were actively involved in about a third to slightly over half of handovers. Approximately four people were present at the bedside handover; generally the team leader of the outgoing shift and all three team members of the oncoming shift. On average, each bedside handover took just over a minute. 
Table 1 here

Thirty-four in-depth interviews were undertaken (Table 2). As expected, the vast majority of interviewees were female, with about half 40 years or older. Most were bedside nurses. Overall, almost half worked full-time and on average had 10 or more years of experience.

Table 2 here

\section{$\underline{\text { Structures }}$}

Table 3 illustrates that handover generally occurred between the teams; not as a 'whole of ward' handover. It contains both a description of the handover structures and participants' comments that reflect these structures. The outgoing team leader led the handover, and was generally the only outgoing staff member attending the bedside, thereby limiting bedside crowding. All of the oncoming team attended the handover. Patient non-participation is explained in Table 3. A computer generated handover sheet that included all patients on the ward was used in both hospitals (Table 3). Components of the health record, consisting of the observation record, medication record, fluid balance sheet and risk assessment forms (falls, pressure ulcer etc.) were at the bedside for use during the handover.

Table 3 here

\section{$\underline{\text { Processes }}$}

The processes prior to, during and after the handover were identified (Figure 1). Prior to handover, patient allocation was completed and the handover sheet updated, although this update did not always occur. Just prior to the handover, patients were informed that handover 
would shortly take place and were asked if they required any assistance, in order to limit disruptions during the actual handover. Visitors were requested to wait in the lounge area during handover; however, with the patient's agreement, families remained.

The content of handover varied according to nurses’ familiarity with the patients. Key essential information was prompted by patients’ presence. One nurse stated “You can get a lot more observation and draw a lot more information when you actually look and see for yourself." Patients and their family were invited to comment or ask questions near the end of the handover. Medical jargon was kept to a minimum. Both a safety scan and a medication review were undertaken. The scan involved checking that the call bell was in reach, that suction, oxygen and other equipment was working properly and visualisation of dressings, intravenous sites etc. Sensitive information was handed over away from the bedside or written on the handover sheet. Shift co-ordinators, who oversaw each ward, either attended one team's bedside handovers followed by a short report from the other oncoming team leaders, or they attended a separate handover from the outgoing shift co-ordinator. One nurse explained: "The[shift] coordinator normally goes to get the handover from the area that they're working in ... and then a brief handover of what's happening with the rest of the ward.” Between handovers, staff that started at variable times were assigned to particular teams. Using the handover sheet as a guide, they were assigned a number of tasks until they could attend an upcoming handover.

\section{$\underline{\text { Outcomes }}$}

Table 4 contains the outcomes as perceived by the nurses interviewed. These nurses thought that the accuracy of the handover was improved, and that bedside handover promoted patient centred care and improvements to nursing services. Statements nurses made related to each of these outcomes are included in Table 4. 
Table 4 here

\section{Discussion}

Based on our study of over 500 bedside nursing handovers and 34 interviews, we generated a template of the structures, processes and outcomes of bedside handover. The findings can be used as a basis for the development of standard operating protocols for its implementation, something only beginning to be documented in the literature ${ }^{3}$. It was interesting that, despite being intended as a patient-centred approach, patients actively participated in less than half of observed handovers, a finding also confirmed in a survey ${ }^{30}$. While our interview participants explained legitimate reasons for this low participation rate, it appears that nurses must work to actively involve patients.

Only one hospital adopted $\mathrm{SBAR}^{27,28}$ in their handovers. SBAR formalizes handover content, which may create trust within the healthcare team, as all team members are provided with objective information in a standardised format. ${ }^{31}$ Alternatively, such rigid structures may actually have unintended consequences. ${ }^{32}$ Patterson ${ }^{32}$ suggests that instead of using a very structured approach during handovers, transferring information according to priority, with the 'most important first,' may help oncoming staff get 'the story' more quickly. The suggestion for 'most important first' was not identified in our study.

This study has shown that one important difference between bedside and other forms of handover is that nurses receive report on only their assigned patients, and not the other patients on the ward. This maybe problematic when nurses are called to assist with the care of other patients, however participants explained that they used the printed handover sheet to guide them, a practice also used in other organisations. ${ }^{32}$ The handover sheet played a key role both during and after handover, when variable start times were part of the roster, and meant 
that some nursing staff would miss the bedside handover. Ensuring that the handover sheet contains the important patient information and is updated regularly to ensure its accuracy is clearly crucial.

In this study, sensitive information was discussed away from the patient bedside so that no patients or visitors could hear this conversation. While the nurses used common sense to identify what was sensitive, the extent to which their perceptions were shared by patients was not explored. Further, as both of the study sites were relatively large, it was unlikely that patients knew each other in their everyday lives. However, in smaller, regional hospitals, it may be more likely that patients are known to each other. The extent to which bedside handover is appropriate in these situations remains unknown. A previous survey showed that almost $30 \%$ of 74 patients perceived the presence of other patients in the room during bedside handover as somewhat disturbing. ${ }^{30}$ It appears that nurses need to carefully consider how sensitive information is shared during bedside handover.

Nurses perceived bedside handover in a positive light, believing it improved the accuracy of the information they handed over, however no comparison was done with other handover types, so this perception may not be accurate. Our participants said that patients' presence not only prompted outgoing nurses to remember information that should be passed on, it also prompted oncoming nurses to ask questions and seek clarification, which may account for the perceived accuracy of bedside handover.

In conclusion, this case study of bedside handover used by nursing staff in six wards in two hospitals provides a description of its structures, processes and perceived outcomes. This information may be used as the basis for standard operating protocols for more widespread implementation. Importantly, to date, measurable benefits of bedside handover for nurses and patients are yet to be firmly established. 


\section{Acknowledgements}

Financial support from the Australian Commission on Safety and Quality in Health Care is gratefully acknowledged as is the support of the participating hospitals. 


\section{References}

1. Australian Commission for Safety and Quality in Health Care. Nine priority programs. 2008. Available from URL: http://www.safetyandquality.gov.au. Accessed 16 March 2009.

2. World Health Organization. Communication during patient hand-overs. Patient Safety Solutions, 1(3). Available from URL:

http://www.who.int/patientsafety/solutions/patientsafety/en/index.html. Accessed 16 March 2009.

3. Chaboyer W, McMurray A, Johnson J, Hardy L, Wallis M, Chu FY. Bedside Handover: Quality Improvement Strategy to "Transform Care at the Bedside". (in press). Journal of Nursing Care Quality (prepublication print).

4. Australian Medical Association. Safe handover: Safe patients; guidelines on clinical handover for clinicians and managers. 2006. Available from URL:

http://www.ama.com.au/web.nsf/doc/WEEN-6XFDKN/pdf. Accessed 10 March 2009.

5. Rutherford P, Lee B, Greiner A. Transforming care at the bedside. Cambridge, Ma: Institute for Healthcare Innovations, 2004.

6. Martin SC, Greenhouse PK, Merryman T, Shovel J, Liberi CA, Konzier J.

Transforming care at the bedside: implementation and spread model for singlehospital and multihospital systems. Journal of Nursing Administration 2007; 37: 444451.

7. O'Connell B, Macdonald K, Kelly C. Nursing handover: it's time for a change. Contemporary Nurse 2008; 30: 2-11.

8. Miller C. Ensuring continuing care: styles and efficiency of the handover process. Australian Journal of Advanced Nursing 1998; 16: 23-27.

9. O'Connell B, Penney W. Challenging the handover ritual. Recommendations for research and practice. The Collegian 2001; 8: 14-18.

10. Philpin S. 'Handing over': transmission of information between nurses in an intensive therapy unit. Nursing in Critical Care 2006; 11: 86-93.

11. Kerr MP. A qualitative study of shift handover practice and function from a sociotechnical perspective. Journal of Advanced Nursing 2002; 37: 125-134.

12. Lally S. An investigation into the functions of nurses' communication at the inter-shift handover. Journal of Nursing Management 1999; 7: 29-36.

13. Davies S, Priestley MJ. A reflective evaluation of patient handover practices. Nursing Standard 2006; 20: 49-52. 
14. Dowding D. Examining the effects that manipulating information given in the change of shift report has on nurses' care planning ability. Journal of Advanced Nursing 2001; 33: 836-846.

15. McKenna L, Walsh K. Changing handover practices: one private hospital's experiences. International Journal of Nursing Practice 1997; 3: 128-132.

16. Cahill J. Patient's perceptions of bedside handovers. Journal of Clinical Nursing 1998; 7: 351-359.

17. Broekhuis M, Veldkamp C. The usefulness and feasibility of a reflexivity method to improve clinical handover. Journal of Evaluation in Clinical Practice 2007; 13: 109115.

18. Currey J, Browne J, Botti M. Haemodynamic instability after cardiac surgery: nurses' perceptions of clinical decision-making. Journal of Clinical Nursing 2006; 15: 10811090.

19. Coulter A, Ellins J. Effectiveness of strategies for informing, educating, and involving patients. British Medical Journal 2007; 335: 24-27.

20. Sexton A, Chan C, Elliott M, Stuart J, Jayasuriya R, Crookes P. Nursing handovers: do we really need them? Journal of Nursing Management 2004; 12: 37-42.

21. Parker J, Gardner G, Wiltshire J. Handover: the collective narrative of nursing practice. Australian Journal of Advanced Nursing 1992; 9: 31-37.

22. Watkins S. Bedside manners. Nursing Times 1993; 89: 42-43.

23. Yin RK. Case Study Research: Design and Methods. 3rd ed. Thousand Oaks CA: Sage, 2003.

24. Stake R. Case studies. In: Denzin N, Lincoln Y (eds). Handbook of qualitative research. Thousand Oaks: Sage, 1994; 236-247.

25. Kyburz-Graber R. Does case-study methodology lack rigour? The need for quality criteria for sound case-study research, as illustrated by a recent case in secondary and higher education. Environmental Education Research 2004; 10: 53-66.

26. Donabedian A. The role of outcomes in quality assessment and assurance. Quality Review Bulletin 1992; 18: 356-360.

27. Haig KM, Sutton S, Whittington J. SBAR: a shared mental model for improving communication between clinicians. Joint Commission's Perspectives on Patient Safety 2006; 32: 167-175.

28. Mikos K. Monitoring handoffs for standardization. Nurse Manager 2007; 38: 16-20.

29. DeSantis L, Ugarriza DN. The concept of theme as used in qualitative nursing research. Western Journal of Nursing Research 2000; 22: 351-372. 
30. Timonen L, Sihvonen M. Patient participation in bedside reporting on surgical wards. Journal of Clinical Nursing 2000; 9: 542-548.

31. Shortell S, Kaluzny A. Health care management, $5^{\text {th }}$ edition. New York: Thomson Delmar Learning, 2006.

32. Patterson ES. Structuring flexibility: the potential good, bad and ugly in standardisation of handovers. Quality and safety in health care 2008; 17: 4-5. 
Table 1: Observational Findings

\begin{tabular}{|c|c|c|c|}
\hline Observations & $\begin{array}{c}\text { Hospital A } \\
n=263 \\
\text { Frequency (\%) }\end{array}$ & $\begin{array}{c}\text { Hospital B } \\
n=269 \\
\text { Frequency (\%) }\end{array}$ & $\begin{array}{c}\text { Total } \\
\mathrm{n}=532 \\
\text { Frequency }(\%)\end{array}$ \\
\hline \multicolumn{4}{|l|}{ Type of Ward } \\
\hline Medical & $186(71 \%)$ & $103(38 \%)$ & 289 (54\%) \\
\hline Surgical & $\mathrm{N} / \mathrm{A}$ & $93(35 \%)$ & $93(17 \%)$ \\
\hline Combined medical surgical & $\mathrm{N} / \mathrm{A}$ & $73(27 \%)$ & $73(14 \%)$ \\
\hline Rehabilitation & 77 (29\%) & N/A & $77(14 \%)$ \\
\hline \multicolumn{2}{|l|}{ SBAR } & \multirow[t]{5}{*}{ Not used } & \multirow[t]{5}{*}{ N/A } \\
\hline Situation & $171(65 \%)$ & & \\
\hline Background & $148(56 \%)$ & & \\
\hline Assessment & $118(45 \%)$ & & \\
\hline Recommendations & $156(59 \%)$ & & \\
\hline \multirow[t]{2}{*}{ Active patient involvement } & 85 (32\%) & $154(57 \%)$ & $239(45 \%)$ \\
\hline & Mean (SD) & Mean (SD) & Mean (SD) \\
\hline $\begin{array}{l}\text { Number of staff at the } \\
\text { bedside }\end{array}$ & $4.0( \pm 1.23)$ & $3.7( \pm 1.17)$ & $3.8( \pm 1.2)$ \\
\hline Time for handover & $78( \pm 45)$ sec & $74( \pm 57) \mathrm{sec}$ & $76( \pm 51)$ sec \\
\hline
\end{tabular}


Table 2: Characteristics of the Participants Interviewed

\begin{tabular}{lccc}
\hline Characteristic & $\begin{array}{c}\text { Hospital A } \\
\mathrm{n}=15 \\
\text { Frequency } \\
(\%)\end{array}$ & $\begin{array}{c}\text { Hospital B } \\
\mathrm{n}=19 \\
\text { Frequency } \\
(\%)\end{array}$ & $\begin{array}{c}\text { Total } \\
\mathrm{n}=34 \\
\text { Frequency } \\
(\%)\end{array}$ \\
\hline Female & $15(100 \%)$ & $17(89.5 \%)$ & $32(94.1 \%)$ \\
\hline $\begin{array}{l}\text { Age group (years) } \\
<30\end{array}$ & $6(40.0 \%)$ & $1(5.3 \%)$ & $7(20.6 \%)$ \\
$30-<40$ & $1(6.7 \%)$ & $9(47.4 \%)$ & $10(29.4 \%)$ \\
$40-<50$ & $3(20.0 \%)$ & $8(42.1 \%)$ & $11(32.3 \%)$ \\
$\geq 50$ & $5(33.3 \%)$ & $1(5.3 \%)$ & $6(17.6 \%)$ \\
\hline Nursing Classification & $4(26.7 \%)$ & $3(15.8 \%)$ & $7(20.6 \%)$ \\
$\quad$ Enrolled Nurse (practical) & $8(53.3 \%)$ & $7(36.8 \%)$ & $15(44.1 \%)$ \\
Level 1 RN (bedside) & $3(20.0 \%)$ & $4(21.1 \%)$ & $7(20.6 \%)$ \\
Level 2 RN (team leader) & 0 & $5(26.3)$ & $5(14.7)$ \\
Level 3 RN (manager, educator) & $10(66.7 \%)$ & $6(31.6 \%)$ & $16(47.1 \%)$ \\
\hline Full-Time & Mean (SD) & Mean (SD) & Mean (SD) \\
\hline & $10.9(10.8)$ & $14.7(8.5)$ & $13.1(9.6)$ \\
\hline Years of experience & & & \\
\hline
\end{tabular}


Table 3: Overview of Bedside Handover Structures

\begin{tabular}{|c|c|c|}
\hline Structure & Description & Participants' Comments \\
\hline Staff & $\begin{array}{l}\text { - } \quad \text { Team nursing used to deliver care. } \\
\text { - Handover attended by team leader of the outgoing staff and all } \\
\text { members of the receiving staff. } \\
\text { - Shift co-ordinator's attendance at bedside handovers varied } \\
\text { according to whether they have a patient load. }\end{array}$ & $\begin{array}{l}\text { "If you speak to them [patients] during the process they feel } \\
\text { like they're involved...they know straight away who’s } \\
\text { looking after them, they can put a name to the faces" }\end{array}$ \\
\hline Patients & $\begin{array}{l}\text { Patients who generally did not participate in the handover } \\
\text { included those that were: asleep, hard of hearing, confused, } \\
\text { comatose, in isolation and those who did not want handover to } \\
\text { occur at their bedside. }\end{array}$ & $\begin{array}{l}\text { "If they’re [patients] uncomfortable obviously you don’t have } \\
\text { to do theirs at the bedside, you can do theirs outside the room } \\
\text { or in the nurses station.” }\end{array}$ \\
\hline $\begin{array}{l}\text { Handover } \\
\text { sheet }\end{array}$ & $\begin{array}{l}\text { - Computer generated handover sheet was updated regularly, and } \\
\text { contained information about all patients on the ward. } \\
\text { - Individual patient information included: age, gender, admitting } \\
\text { diagnosis and medical history, social history, discharge } \\
\text { planning, changes in clinical condition, and sensitive or } \\
\text { confidential information. }\end{array}$ & $\begin{array}{l}\text { "The handover sheet’s normally just NFR [not for } \\
\text { resuscitation], isolation and their history .... and anything } \\
\text { relevant um so you know if they come from a nursing home } \\
\text { or if they normally live alone and might need some } \\
\text { community help before they go home.” }\end{array}$ \\
\hline
\end{tabular}


Table 4: Nurses’ Perceptions of the Outcomes of Bedside Handover

\begin{tabular}{|c|c|c|}
\hline Outcome & Description & Participants' Comments \\
\hline $\begin{array}{l}\text { Improving } \\
\text { accuracy }\end{array}$ & $\begin{array}{l}\text { - A visual view of the patient prompts } \\
\text { recall of information. } \\
\text { - Reporting of observational data is more } \\
\text { precise. } \\
\text { - Bedside handover strengthens } \\
\text { accountability for accurate information } \\
\text { - Improves communication - staff tend to } \\
\text { stick to relevant information in front of } \\
\text { patients. }\end{array}$ & $\begin{array}{l}\text { - "We get more accurate } \\
\text { information and have a } \\
\text { better understanding of } \\
\text { our patients." } \\
\text { - "It improves our } \\
\text { communication as it } \\
\text { forces you to focus on } \\
\text { what you're supposed to } \\
\text { be doing for the patient, } \\
\text { and explaining it in a } \\
\text { professional manner." }\end{array}$ \\
\hline $\begin{array}{l}\text { Promoting } \\
\text { patient } \\
\text { centred care }\end{array}$ & $\begin{array}{l}\text { Patients are made to feel they are part of } \\
\text { the process of care. }\end{array}$ & $\begin{array}{l}\text { - "It is an opportunity for } \\
\text { real patient } \\
\text { engagement." } \\
\text { - "Bedside handover lets } \\
\text { patients know that } \\
\text { they're actually valued } \\
\text { and it also gives the } \\
\text { family an opportunity to } \\
\text { participate as well” }\end{array}$ \\
\hline $\begin{array}{l}\text { Service } \\
\text { delivery } \\
\text { improvements }\end{array}$ & $\begin{array}{l}\text { - Continuity of care is improved. } \\
\text { - Care is more holistic as it is informed } \\
\text { by input from the patient. } \\
\text { - Clinical knowledge is more consistent } \\
\text { and transparent, which provides a basis } \\
\text { for teaching junior staff and students } \\
\text { - Better preparation for handover - staff } \\
\text { try to appear prepared and efficient, } \\
\text { which improves patient confidence in } \\
\text { caregivers. }\end{array}$ & $\begin{array}{l}\text { - "We are happy because } \\
\text { handover is quicker." } \\
\text { "There are more } \\
\text { opportunities for } \\
\text { teaching." }\end{array}$ \\
\hline
\end{tabular}




\section{Prior to Handover}

- Patient allocation completed

- Handover sheet updated and printed for staff

- Patient informed that handover will commence shortly

- Visitors requested to return to the waiting room

- With patient's permission, family remain at the bedside

\begin{tabular}{|c|}
\hline $\begin{array}{ll}\text { During Handover } \\
\text { - } & \text { Patient is introduced by the } \\
\text { outgoing staff } \\
\text { - } \\
\text { Information exchanged } \\
\text { - } \quad \text { Pometimes using SBAR } \\
\text { - } \quad \text { Safety scan conducted } \\
\text { - } \text { Medication sheet reviewed } \\
\text { - } \quad \text { Sensitive information } \\
\text { conveyed away from the } \\
\text { bedside or written on the } \\
\text { handover sheet }\end{array}$ \\
\hline
\end{tabular}

\section{After Handover}

- Staff who start at variable times are assigned to established teams

- Handover sheet is used as a guide

- New staff undertake tasks within their team until the next handover occurs

Figure 1: Summary of the Bedside Handover Process 